A. Juutilainen $\cdot$ S. Lehto $\cdot$ T. Rönnemaa $\cdot$

K. Pyörälä • M. Laakso

\title{
Proteinuria and metabolic syndrome as predictors of cardiovascular death in non-diabetic and type 2 diabetic men and women
}

Received: 23 February 2005 / Accepted: 5 September 2005 / Published online: 20 December 2005

(C) Springer-Verlag 2005

\begin{abstract}
Aims/hypothesis: Proteinuria predicts cardiovascular disease (CVD), but it is unclear whether this is explained by the association of the metabolic syndrome with proteinuria. Therefore, we investigated proteinuria and the metabolic syndrome as independent predictors of CVD death in men and women. Methods: The cohort comprised 574 non-diabetic men, 707 non-diabetic women, 371 diabetic men and 349 diabetic women, all free of CVD at baseline. Modified World Health Organization criteria were used to define the metabolic syndrome, and a urinary protein concentration of $\geq 0.1 \mathrm{~g} / 1$ ( or $\geq 0.2 \mathrm{~g} / \mathrm{l}$ ) to define proteinuria. The endpoint was CVD mortality during the 18-year follow-up. Results: Among non-diabetic men, CVD mortality per 1,000 person-years was as follows: no metabolic syndrome, no urinary protein group: 5.3; no metabolic syndrome, positive for urinary protein: 8.9; positive for metabolic syndrome, no urinary protein: 13.3; and positive for metabolic syndrome and urinary protein: 14.9. For non-diabetic women the corresponding values were: $0.9,2.3,4.9$ and 7.9 , respectively. Among diabetic men, CVD mortality per 1,000 person-years was $15.2,32.5$, 23.6 and 42.0 for the respective groups. Among diabetic women it was $25.3,38.0,26.3$ and 40.3 (urinary protein in all cases defined as $\geq 0.1 \mathrm{~g} / \mathrm{l}$ ). In multivariate Cox models including both urinary protein and metabolic syndrome, the hazard ratios (HRs, 95\% CI) of proteinuria for CVD mortality were $1.5(0.9-2.4)$ in non-diabetic men, $1.8(0.8-$ 4.2) in non-diabetic women, $1.6(1.0-2.6)$ in diabetic men and $1.6(1.1-2.3)$ in diabetic women. Urinary protein as a
\end{abstract}

\footnotetext{
A. Juutilainen $\cdot$ S. Lehto

K. Pyörälä · M. Laakso $(\bowtie)$

Department of Medicine,

University of Kuopio,

Kuopio, 70210 Finland

e-mail: markku.laakso@kuh.fi

Tel.: +358-17-172151

T. Rönnemaa

Department of Medicine,

University of Turku,

Turku, Finland
}

continuous variable was associated with CVD mortality in all groups. The corresponding HRs for metabolic syndrome were: 1.6 (0.9-2.7), 4.0 (1.7-9.7), 1.5 (1.1-2.0) and 1.1 (0.8-1.5). Conclusions/interpretation: Proteinuria predicted CVD mortality independently of the presence of metabolic syndrome in non-diabetic and diabetic subjects. Metabolic syndrome predicted CVD mortality in nondiabetic women and in diabetic men, independently of the presence of proteinuria.

Keywords Cardiovascular disease $\cdot$ Metabolic syndrome Proteinuria

Abbreviations CVD: cardiovascular disease $\cdot$ HR: hazard ratio - NCEP: National Cholesterol Education Program OR: odds ratio

\section{Introduction}

Microalbuminuria and proteinuria predict cardiovascular disease (CVD) events, not only in diabetic [1-7], but also in non-diabetic individuals [5, 8-12]. Microalbuminuria was included in the WHO definition of the metabolic syndrome in 1998 [13], but since then there has been debate about microalbuminuria as a component of the metabolic syndrome [14]. Microalbuminuria could be a secondary indicator of vascular dysfunction reflecting the effects of risk factor components of metabolic syndrome, because no independent association of albuminuria with the insulin resistance syndrome has been found [15]. Furthermore, although microalbuminuria is present in $10-40 \%$ of patients with essential hypertension [16], its association with insulin resistance in hypertensive patients has remained controversial $[17,18]$. However, several components of metabolic syndrome are associated with proteinuria in both non-diabetic and type 2 diabetic subjects [19-21].

No prospective population-based studies have examined whether proteinuria and metabolic syndrome defined without proteinuria are independent predictors of CVD mortal- 
ity in non-diabetic and type 2 diabetic subjects. Therefore, we investigated this question in an 18-year follow-up study of Finnish non-diabetic and type 2 diabetic men and women, with a particular focus on the impact of sex on the predictive value of proteinuria and metabolic syndrome.

\section{Subjects and methods}

Patients A detailed description of study participants has been published previously [22]. Altogether 1,059 subjects (581 men, 478 women) with type 2 diabetes, aged 4564 years, born and living in the Turku University Hospital district in West Finland and in the Kuopio University Hospital district in East Finland were identified through a national drug reimbursement register. A random sample of 1,373 non-diabetic subjects (638 men, 735 women), aged 45-64 years, born and living in the two study areas, was taken from the population register and invited to participate. Subjects with type 1 diabetes were excluded on the basis of the age of onset of diabetes, history of ketoacidosis, and glucagon-stimulated C-peptide measurement at baseline. The present study included 1,281 non-diabetic subjects (574 men, 707 women) and 720 subjects with type 2 diabetes (371 men, 349 women) who were free of clinically significant CVD (verified previous myocardial infarction, stroke or lower extremity amputation due to peripheral arterial disease) at baseline, who were not treated with insulin and for whom complete data on insulin or urinary protein analyses were available. Subjects with concurrent clinically diagnosed urinary tract infections were excluded. Of the diabetic subjects, 118 were treated with diet only and 602 with oral hypoglycaemic drugs. The mean age \pm SD was $54.4 \pm 5.6$ in non-diabetic men, $54.8 \pm 5.5$ in non-diabetic women, $57.0 \pm 5.2$ in diabetic men, and $58.8 \pm 4.7$ years in diabetic women, and the mean BMI was $26.1 \pm 3.2,27.0 \pm$ $4.6,28.3 \pm 4.6$ and $30.8 \pm 5.9 \mathrm{~kg} / \mathrm{m}^{2}$, respectively. The duration of diabetes was $7.5 \pm 3.6$ years in both diabetic men and women.

Baseline study The baseline examination, conducted in 1982-1984, has been described in detail previously [22]. Two investigators (T. Rönnemaa, M. Laakso) reviewed the hospital records of those participants who reported that they had been hospitalised for CVD. Modified WHO criteria for definite or possible myocardial infarction based on chest pain symptoms, ECG changes, and cardiac enzymes were used to verify the diagnosis of previous myocardial infarction [23]. The diagnosis of previous stroke was based on WHO criteria: a neurological deficit observed by a physician and persisting for $>24 \mathrm{~h}$, without another disease explaining the symptoms [24]. Non-traumatic lower extremity amputations were recorded. Subjects were classified as having hypertension if they were receiving drug treatment for hypertension or if systolic blood pressure was $\geq 160 \mathrm{mmHg}$ or diastolic blood pressure was $\geq 95 \mathrm{mmHg}$ in the sitting position after a 5 -min rest. Standing height and body weight were measured.
Biochemical methods All laboratory specimens were taken at 08:00 hours after a 12-h fast. The analyses were performed in duplicate except for $\mathrm{HbA}_{1} \mathrm{c}$. Serum total cholesterol and triglycerides were determined enzymatically (Boehringer). Serum HDL cholesterol was determined enzymatically after precipitation of LDL and VLDL with dextran sulphate- $\mathrm{MgCl}_{2}$. The day-to-day variations in measurements were $2.2 \%$ for cholesterol and $4.4 \%$ for triglycerides, and intra-assay variations were $1.6 \%$ for cholesterol and $2.6 \%$ for triglycerides. Plasma glucose was determined with the glucose oxidase method (Boehringer). Plasma insulin concentration was determined by a commercial RIA method (antisera M8170 and 8309; Novo, Copenhagen, Denmark). The day-to-day and intra-assay variations were 8.4 and $7.0 \%$, respectively. Total urinary protein concentration was measured from the morning spot urine specimen with the Coomassie brilliant blue method (Bio-Rad Laboratories, Hercules, CA, USA) [25].

Definition of metabolic syndrome and proteinuria A modified WHO definition was used to determine the presence of metabolic syndrome as in the DECODE study [26]. Hyperinsulinaemia, with fasting insulin equal to or higher than the highest quartile in non-diabetic subjects, as a surrogate marker for insulin resistance, was used as a compulsory component of metabolic syndrome, and additionally the presence of at least two of the following four components of metabolic syndrome was required: (1) elevated fasting glucose $\geq 6.1 \mathrm{mmol} / 1$ or known diabetes; (2) raised systolic or diastolic blood pressure $(\geq 140 / 90 \mathrm{mmHg})$ or the use of antihypertensive drugs; (3) dyslipidaemia with triglycerides $\geq 1.7 \mathrm{mmol} / 1$ or HDL cholesterol $<0.9 \mathrm{mmol} / 1$ in men and $<1.0 \mathrm{mmol} / 1$ in women; and (4) obesity with BMI $>30 \mathrm{~kg} / \mathrm{m}^{2}$. Data for urinary protein were analysed with two cut-offs for urinary protein concentration $(\geq 0.1$ and $\geq 0.2 \mathrm{~g} / \mathrm{l}$ ). Subjects were assigned to groups as follows: (1) no metabolic syndrome, no urinary protein; (2) no metabolic syndrome, positive for urinary protein; (3) positive for metabolic syndrome, no urinary protein; and (4) positive for metabolic syndrome and urinary protein.

Follow-up study The follow-up period lasted until 1 January 2001. Information on the vital status of the participants and copies of death certificates of all deceased subjects were obtained from the Cause-of-Death Register (Statistics Finland). In the final classification of causes of death, hospital records and autopsy records, if available, were also used. The causes of death were reviewed by two of us (A. Juutilainen, S. Lehto). The endpoint used in this study was CVD death, specified as codes of 390-459 of the International Classification of Diseases 9.

Statistical methods Data analyses were conducted with the SPSS 11.5.1 programs (SPSS, Chicago, IL, USA). The results for continuous variables are given as mean $\pm \mathrm{SD}$, and for categorical variables as percentages, unless otherwise indicated. The group differences in continuous variables were analysed by Student's $t$-test, except for the duration of 


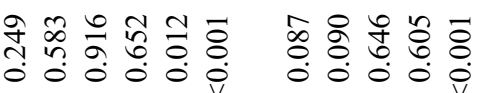

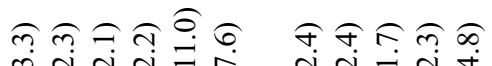
in e

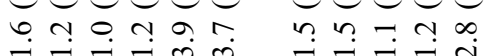

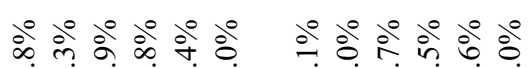

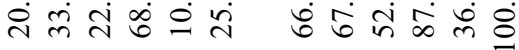

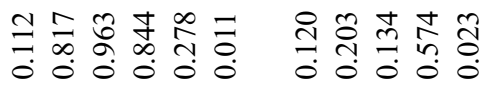

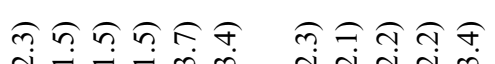

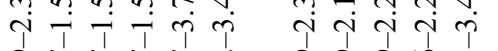

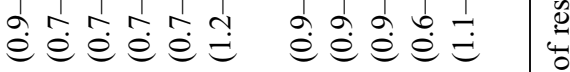

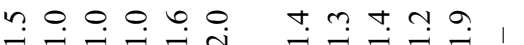

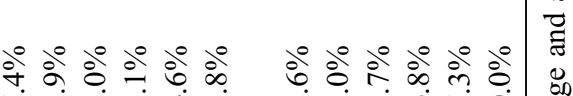

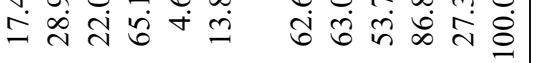

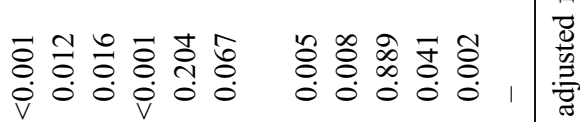

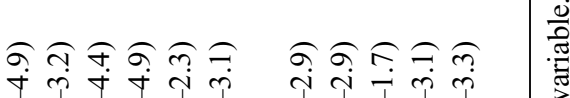

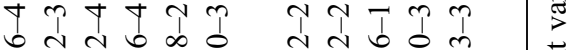

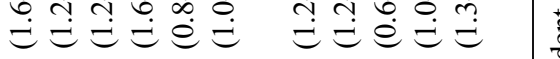

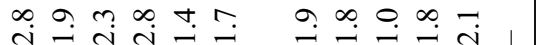

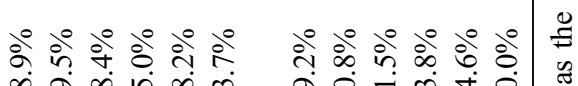

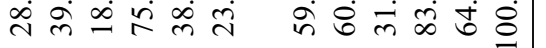

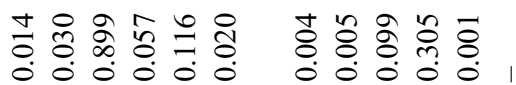

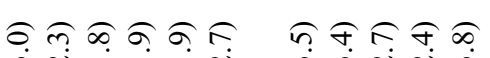

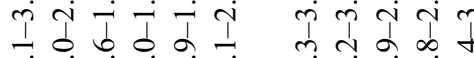

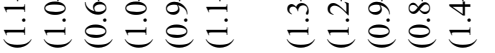

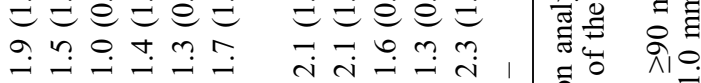

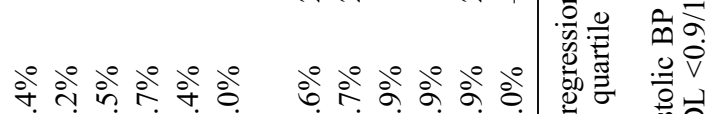

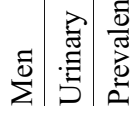

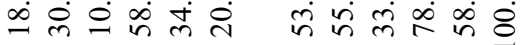
若

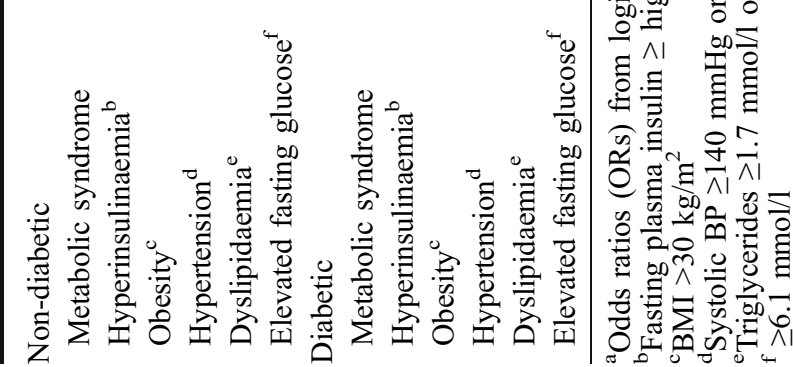


diabetes, which was analysed by Mann-Whitney $U$-test. The $\chi^{2}$-test was used to test differences in categorical variables. The non-parametric Jonckheere-Terpstra test was used to test trends of continuous variables over the groups formed by the number of the components of the metabolic syndrome. Logistic regression analysis was performed to evaluate the associations of metabolic syndrome and its components with proteinuria as the dependent variable. Logarithmic transformations were used for all statistical testing concerning triglycerides, fasting insulin and urinary protein to correct their skewed distribution. Cox proportional hazards models, adjusted for age, sex, area of residence, current smoking and total cholesterol, were used to assess the association of metabolic syndrome, proteinuria and their different combinations with the risk of CVD death. The cumulative incidence of CVD death was depicted by Kaplan-Meier curves. A $p$-value less than 0.05 was considered statistically significant, with the exception of $p<0.10$ when testing interactions.

Approval of the ethics committees The ethics committees of the Kuopio University Hospital and the Turku University Central Hospital approved the study. All study subjects gave informed consent.
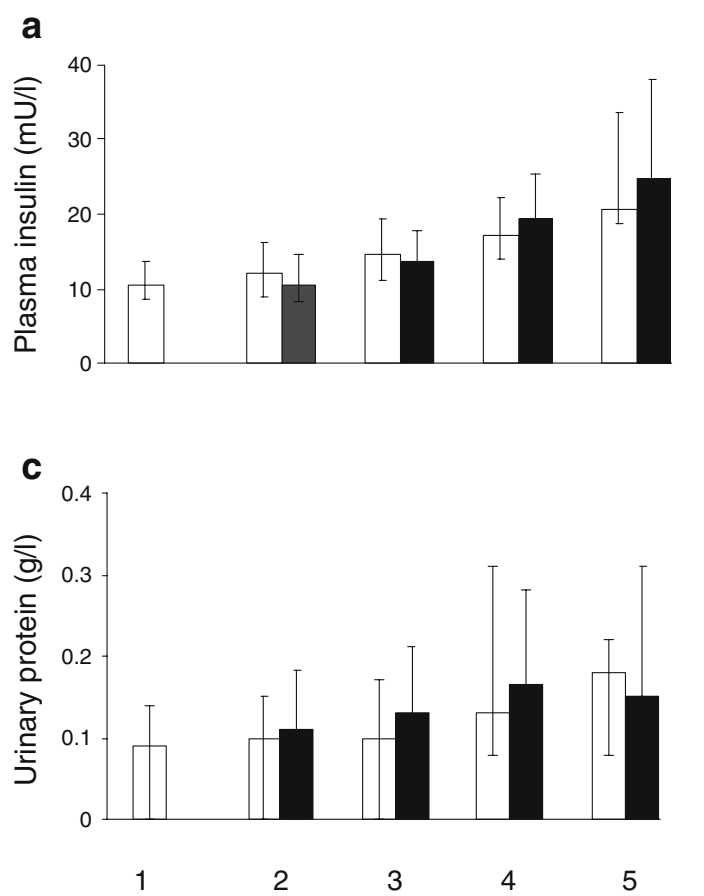

Number of components of the metabolic syndrome

Fig. 1 The medians and interquartile ranges for fasting plasma insulin $(\mathbf{a}, \mathbf{b})$ and urinary protein $(\mathbf{c}, \mathbf{d})$ in non-diabetic and diabetic men $(\mathbf{a}, \mathbf{c})$ and women $(\mathbf{b}, \mathbf{d})$ according to the number of components of the metabolic syndrome other than hyperinsulinaemia. Open bars

\section{Results}

Prevalence of the metabolic syndrome and proteinuria at baseline Metabolic syndrome was present in $14.6 \%$ of nondiabetic men, in $12.7 \%$ of non-diabetic women, in $49.1 \%$ of diabetic men and in $58.7 \%$ of diabetic women. Proteinuria, using the cut-offs of $\geq 0.1 \mathrm{~g} / \mathrm{l} / \geq 0.2 \mathrm{~g} / \mathrm{l}$, was present in $53.1 \% / 13.2 \%$ of non-diabetic men, in $30.8 \% / 6.8 \%$ of nondiabetic women, in $75.5 \% / 35.0 \%$ of diabetic men, and in $65.0 \% / 32.1 \%$ of diabetic women.

When the cut-off for proteinuria was increased from 0.1 to $0.2 \mathrm{~g} / 1$ the prevalence of metabolic syndrome increased in non-diabetic men, but the increase was less in non-diabetic women, diabetic men, and diabetic women (Table 1). With regard to the prevalence of individual components of metabolic syndrome, increasing the cut-off for proteinuria induced the greatest increase for dyslipidaemia and elevated fasting glucose in non-diabetic women, and for obesity in non-diabetic men. The increased prevalence of the other components remained quite modest.

In logistic regression analysis (Table 1), adjusted for age and area of residence, the cross-sectional association of different variables with proteinuria differed according to sex. In non-diabetic men, metabolic syndrome, hyperinsu-
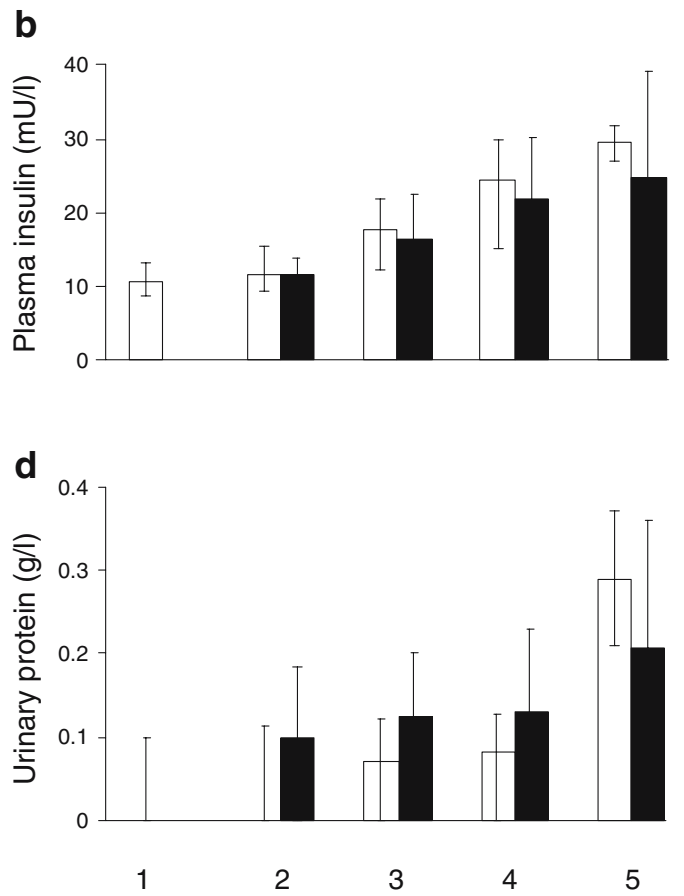

Number of components of the metabolic syndrome

non-diabetic subjects, black bars diabetic subjects. $p$ values for trends: plasma insulin, $p<0.001$ in all subject groups; urinary protein, $p<0.001$ in non-diabetic and diabetic men; $\mathrm{p}=0.008$ in nondiabetic women; $\mathrm{p}=0.006$ in diabetic women 
Table 2 Number of deaths from all-causes $(n)$, number of subjects at risk $(N)$, total death rate/1,000 person-years (DR) and hazard ratio (HR) from Cox model adjusted for age, area of residence, current smoking and total cholesterol in non-diabetic and type 2 diabetic men and women with and without metabolic syndrome and urinary protein during 18-year follow-up

\begin{tabular}{|c|c|c|c|c|c|c|c|c|c|c|c|c|}
\hline & \multicolumn{3}{|c|}{ Non-diabetic men } & \multicolumn{3}{|c|}{ Non-diabetic women } & \multicolumn{3}{|c|}{ Diabetic men } & \multicolumn{3}{|c|}{ Diabetic women } \\
\hline & $n / N$ & DR & $\mathrm{HR}(95 \% \mathrm{CI})$ & $n / N$ & DR & $\operatorname{HR}(95 \% \mathrm{CI})$ & $n / N$ & DR & HR $(95 \% \mathrm{CI})$ & $n / N$ & DR & $\mathrm{HR}(95 \% \mathrm{CI})$ \\
\hline \multicolumn{13}{|c|}{ Metabolic syndrome } \\
\hline No & $132 / 490$ & 16.7 & 1 & $66 / 617$ & 6.2 & 1 & $115 / 189$ & 46.1 & 1 & $87 / 144$ & 45.0 & 1 \\
\hline Yes & $30 / 84$ & 22.7 & $1.2(0.8-1.9)$ & $21 / 90$ & 14.4 & $2.0(1.2-3.3)$ & $132 / 182$ & 60.5 & $1.4(1.1-1.8)$ & $142 / 205$ & 56.0 & $1.3(1.0-1.7)$ \\
\hline \multicolumn{13}{|c|}{ Urinary protein $\geq 0.1 \mathrm{~g} / 1$} \\
\hline No & $65 / 269$ & 14.7 & 1 & $49 / 489$ & 5.8 & 1 & $40 / 91$ & 28.8 & 1 & $65 / 122$ & 38.1 & 1 \\
\hline Yes & $97 / 305$ & 20.3 & $1.3(0.9-1.8)$ & $38 / 218$ & 10.3 & $1.6(1.0$ & $207 / 280$ & 63.0 & $2.1(1$. & $164 / 227$ & 59.3 & 1.6 \\
\hline \multicolumn{13}{|c|}{ Urinary protein $\geq 0.2 \mathrm{~g} / 1$} \\
\hline No & $132 / 498$ & 16.3 & 1 & $71 / 659$ & 6.2 & 1 & $140 / 241$ & 42.7 & 1 & $143 / 237$ & 44.6 & 1 \\
\hline Yes & $30 / 76$ & 26.5 & $1.4(0.9-2.1)$ & $16 / 48$ & 21.1 & $3.2(1.9-5.6)$ & $107 / 130$ & 76.6 & $1.7(1.3-2.3)$ & $86 / 112$ & 68.0 & $1.7(1.3-2.3)$ \\
\hline \multicolumn{13}{|c|}{ Combinations (MetS; UP $\geq 0.1 \mathrm{~g} / \mathrm{l}$ ) } \\
\hline MetS-UP- & $57 / 241$ & 14.4 & 1 & $37 / 437$ & 4.8 & 1 & $24 / 59$ & 26.0 & 1 & $29 / 59$ & 34.9 & 1 \\
\hline MetS-UP+ & $75 / 249$ & 19.2 & $1.3(0.9-1.8)$ & $29 / 180$ & 9.5 & $1.7(1.1-2.9)$ & $91 / 130$ & 57.9 & $2.1(1.3-3.4)$ & $58 / 85$ & 52.5 & $1.7(1.1-2.7)$ \\
\hline MetS+UP- & $8 / 28$ & 17.8 & $1.2(0.6-2.6)$ & $12 / 52$ & 14.6 & $2.6(1.4-5.1)$ & $16 / 32$ & 34.3 & $1.5(0.8-2.9)$ & $36 / 63$ & 41.2 & $1.3(0.8-2.2)$ \\
\hline MetS+UP+ & $22 / 56$ & 25.2 & $1.5(0.9-2.4)$ & $9 / 38$ & 14.3 & $2.3(1.1-4.9)$ & $116 / 150$ & 67.7 & $2.6(1.7-4.1)$ & $106 / 142$ & 63.8 & $2.0(1.3-3.1)$ \\
\hline \multicolumn{13}{|c|}{ Combinations (MetS; UP $\geq 0.2 \mathrm{~g} / \mathrm{l}$ ) } \\
\hline MetS-UP- & $110 / 436$ & 15.5 & 1 & $54 / 579$ & 5.4 & 1 & $70 / 136$ & 36.2 & 1 & $59 / 106$ & 39.8 & 1 \\
\hline MetS-UP+ & $22 / 54$ & 28.3 & $1.6(1.0-2.5)$ & $12 / 38$ & 19.6 & $3.7(1.9-6.9)$ & $45 / 53$ & 80.5 & $2.2(1.5-3.2)$ & $28 / 38$ & 61.8 & $1.8(1.2-2.9)$ \\
\hline MetS+UP- & $22 / 62$ & 22.7 & $1.3(0.8-2.1)$ & $17 / 80$ & 13.0 & $2.1(1.2-3.7)$ & $70 / 105$ & 52.1 & $1.6(1.1-2.2)$ & $84 / 131$ & 48.7 & $1.3(0.9-1.8)$ \\
\hline MetS+UP+ & $8 / 22$ & 22.6 & $1.3(0.6-2.7)$ & $4 / 10$ & 27.1 & $4.0(1.4-11.3)$ & $62 / 77$ & 74.1 & $2.1(1.5-2.9)$ & $58 / 74$ & 71.4 & $2.1(1.4-3.0)$ \\
\hline
\end{tabular}

$M e t S-$ Without metabolic syndrome, MetS+ with metabolic syndrome, $U P$ - without urinary protein, $U P+$ with urinary protein

Table 3 Number of cardiovascular disease (CVD) deaths $(n)$, number of subjects at risk $(N)$, CVD death rate/1,000 person-years (DR) and hazard ratio (HR) from Cox model adjusted for age, area of residence, current smoking and total cholesterol in non-diabetic and type 2 diabetic men and women with and without metabolic syndrome and urinary protein during 18-year follow-up

\begin{tabular}{|c|c|c|c|c|c|c|c|c|c|c|c|c|}
\hline & \multicolumn{3}{|c|}{ Non-diabetic men } & \multicolumn{3}{|c|}{ Non-diabetic women } & \multicolumn{3}{|c|}{ Diabetic men } & \multicolumn{3}{|c|}{ Diabetic women } \\
\hline & $n / N$ & $\mathrm{DR}$ & HR $(95 \% \mathrm{CI})$ & $n / N$ & DR & HR $(95 \% \mathrm{CI})$ & $n / N$ & DR & $\operatorname{HR}(95 \% \mathrm{CI})$ & $n / N$ & DR & HR $(95 \% \mathrm{CI})$ \\
\hline \multicolumn{13}{|c|}{ Metabolic syndrome } \\
\hline No & $56 / 490$ & 7.1 & 1.0 & $14 / 617$ & 1.3 & 1.0 & $65 / 189$ & 26.1 & 1 & $63 / 144$ & 32.6 & 1 \\
\hline Yes & $19 / 84$ & 14.4 & $1.7(1.0-2.9)$ & $9 / 90$ & 6.2 & $4.3(1.8-10.2)$ & $83 / 182$ & 38.1 & $1.6(1.1-2.2)$ & $90 / 205$ & 35.5 & $1.1(0.8-1.6)$ \\
\hline \multicolumn{13}{|c|}{ Urinary protein $\geq 0.1 \mathrm{~g} / 1$} \\
\hline No & $27 / 269$ & 6.1 & 1 & $11 / 489$ & 1.3 & 1 & $25 / 91$ & 18.0 & 1 & $44 / 122$ & 25.8 & 1 \\
\hline Yes & $48 / 305$ & 10.0 & $1.5(1.0-2.5)$ & $12 / 218$ & 3.3 & $2.0(0.9-4.7)$ & $123 / 280$ & 37.4 & $1.8(1.1-2.8)$ & $109 / 227$ & 39.4 & $1.6(1$ \\
\hline \multicolumn{13}{|c|}{ Urinary protein $\geq 0.2 \mathrm{~g} / 1$} \\
\hline No & $60 / 498$ & 7.4 & 1 & $17 / 659$ & 1.5 & 1 & $82 / 241$ & 25.0 & 1 & $93 / 237$ & 29.0 & 1 \\
\hline Yes & $15 / 76$ & 13.3 & $1.5(0.8-2.7)$ & $6 / 48$ & 7.9 & $4.9(1.9-12.7)$ & $66 / 130$ & 47.3 & $1.7(1.2-2.4)$ & $60 / 112$ & 47.4 & $1.9(1.3-2.6)$ \\
\hline \multicolumn{13}{|c|}{ Combinations (MetS; UP $\geq 0.1 \mathrm{~g} / \mathrm{l}$ ) } \\
\hline MetS-UP- & $21 / 241$ & 5.3 & 1 & $7 / 437$ & 0.9 & 1 & $14 / 59$ & 15.2 & 1 & $21 / 59$ & 25.3 & 1 \\
\hline MetS-UP+ & $35 / 249$ & 8.9 & $1.6(0.9-2.8)$ & $7 / 180$ & 2.3 & $2.1(0.7-6.1)$ & $51 / 130$ & 32.5 & $1.9(1.0-3.4)$ & $42 / 85$ & 38.0 & $1.7(1.0-3.0)$ \\
\hline MetS+UP- & $6 / 28$ & 13.3 & $2.2(0.9-5.6)$ & $4 / 52$ & 4.9 & $5.0(1.4-17.5)$ & $11 / 32$ & 23.6 & $1.9(0.9-4.3)$ & $23 / 63$ & 26.3 & $1.2(0.7-2.1)$ \\
\hline MetS+UP+ & $13 / 56$ & 14.9 & $2.3(1.1-4.6)$ & $5 / 38$ & 7.9 & $7.0(2.1-23.4)$ & $72 / 150$ & 42.0 & $2.6(1.5-4.7)$ & $67 / 142$ & 40.3 & $1.8(1.1-3.0)$ \\
\hline \multicolumn{13}{|c|}{ Combinations (MetS; UP $\geq 0.2 \mathrm{~g} / \mathrm{l}$ ) } \\
\hline MetS-UP- & $44 / 436$ & 6.2 & 1 & $10 / 579$ & 1.0 & 1 & $38 / 136$ & 19.6 & 1 & $41 / 106$ & 27.7 & 1 \\
\hline MetS-UP+ & $12 / 54$ & 15.4 & $2.1(1.1-4.0)$ & $4 / 38$ & 6.5 & $7.0(2.1-23.1)$ & $27 / 53$ & 48.3 & $2.2(1.3-3.7)$ & $22 / 38$ & 48.6 & $2.1(1.2-3.5)$ \\
\hline MetS+UP- & $16 / 62$ & 16.5 & $2.2(1.2-4.0)$ & $7 / 80$ & 5.4 & $5.4(2.0-14.6)$ & $44 / 105$ & 32.7 & $1.9(1.2-2.9)$ & $52 / 131$ & 30.2 & $1.2(0.8-1.7)$ \\
\hline MetS+UP+ & $3 / 22$ & 8.5 & $1.1(0.3-3.6)$ & $2 / 10$ & 13.5 & $9.7(2.0-47.0)$ & $39 / 77$ & 46.6 & $2.3(1.4-3.6)$ & $38 / 74$ & 46.8 & $2.0(1.3-3.1)$ \\
\hline
\end{tabular}

$M e t S-$ Without metabolic syndrome, MetS+ with metabolic syndrome, $U P$ - without urinary protein, $U P+$ with urinary protein 
linaemia and elevated fasting glucose were associated with proteinuria, while in diabetic men metabolic syndrome, hyperinsulinaemia and dyslipidaemia were associated with proteinuria (urinary protein $\geq 0.1 \mathrm{~g} / \mathrm{l}$ ). When the $\geq 0.2 \mathrm{-g} / 1$ cut-off point for urinary protein was applied, elevated fasting glucose and dyslipidaemia were associated with proteinuria in non-diabetic women, and dyslipidaemia was associated with proteinuria in diabetic women.

Fasting plasma insulin showed a strong linear association with the number of the components of metabolic syndrome in all four groups. Urinary protein concentrations also showed a positive, but less consistent, linear association with the number of the components of metabolic syndrome (Fig. 1).

Metabolic syndrome and proteinuria as predictors of cardiovascular mortality During the 18-year follow-up 162 of 574 non-diabetic men, 87 of 707 non-diabetic women, 247 of 371 diabetic men and 229 of 349 diabetic women died. The corresponding numbers for death from CVD were: 75 for non-diabetic men, 23 for non-diabetic women, 148 for diabetic men, and 153 for diabetic women.

The presence of metabolic syndrome was significantly associated with all-cause mortality (Table 2) in non-diabetic women and diabetic subjects, and with CVD mortality (Table 3) in non-diabetic subjects and diabetic men. The
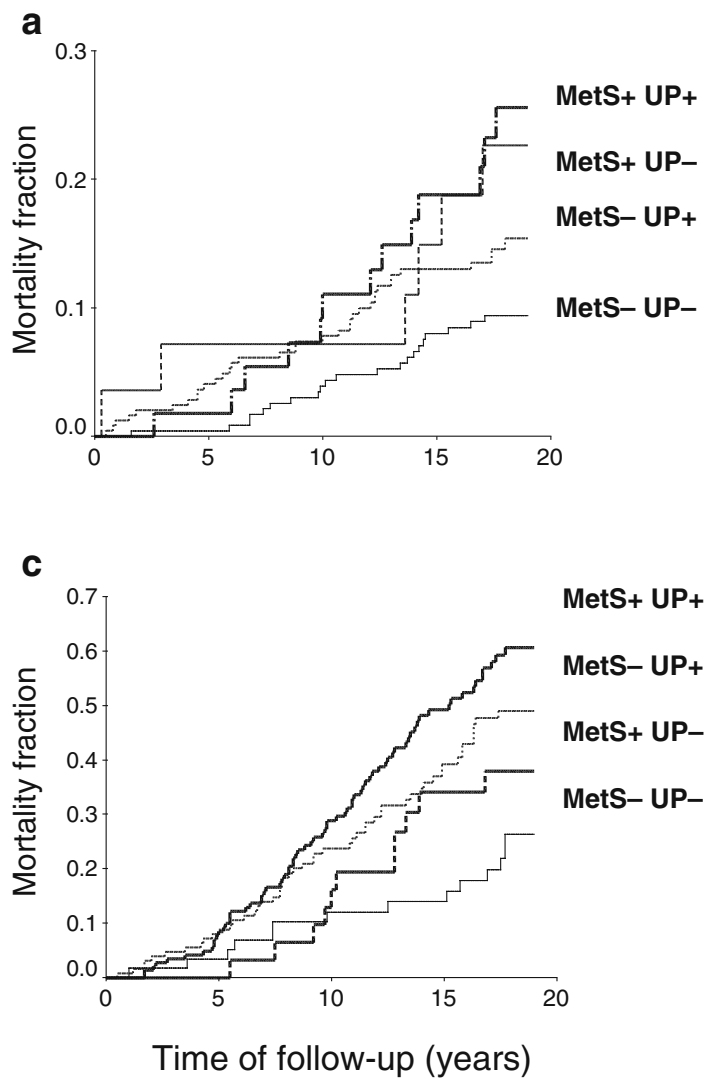

Fig. 2 Cumulative Kaplan-Meier curves for cardiovascular mortality in non-diabetic men (a) and women (b), and in diabetic men (c) and diabetic women (d), according to the presence or absence of presence of proteinuria with both urinary protein cut-offs was significantly associated with all-cause and CVD mortality in diabetic subjects. In non-diabetic women, urinary protein according to both cut-offs was associated with allcause mortality, while a positive finding according to the 0.2 -g/l cut-off point only was associated with CVD mortality. In non-diabetic men, proteinuria with a cut-off point of $0.1 \mathrm{~g} / \mathrm{l}$ was associated with CVD mortality, but not with all-cause mortality.

Compared with the no metabolic syndrome, no urinary protein group, the group that was negative for metabolic syndrome and positive for urinary protein was associated with increased risk of all-cause mortality when both urinary protein cut-offs were applied, except for non-diabetic men with a cut-off point of $0.1 \mathrm{~g} / 1$. Comparing the same groups, the latter was also associated with increased risk of CVD mortality in diabetic subjects with both cut-offs, and in nondiabetic subjects when a cut-off point of $0.2 \mathrm{~g} / \mathrm{l}$ was applied. Compared with the no metabolic syndrome, no urinary protein group, the group that was positive for metabolic syndrome and negative for urinary protein was associated with increased risk of all-cause and CVD mortality in nondiabetic women for both urinary protein cut-offs, and with increased CVD mortality in non-diabetic men for a cut-off point of $0.2 \mathrm{~g} / \mathrm{l}$, and with all-cause and CVD mortality in diabetic men when a cut-off point of $0.2 \mathrm{~g} / 1$ was applied.
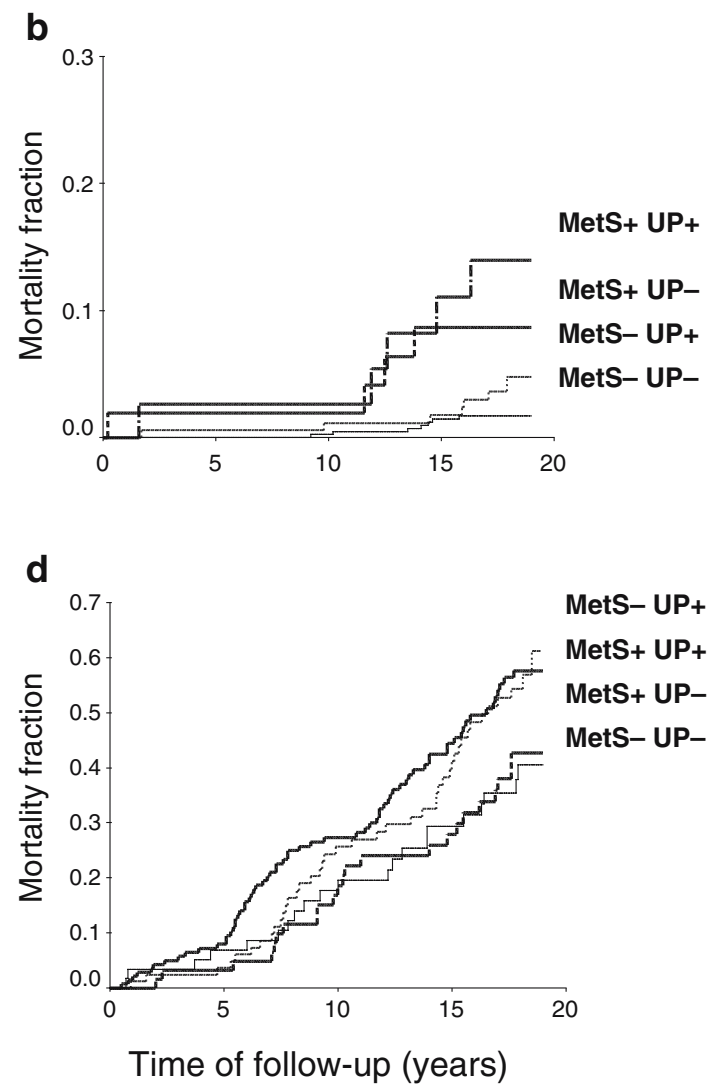

the metabolic syndrome (MetS+, MetS-) and of proteinuria with a cut-off point of $\geq 0.1 \mathrm{~g} / 1$ (UP+, UP-) during 18 years of follow-up 
Table 4 Hazard ratios (HRs) of cardiovascular disease death and sex interactions from three different Cox models including both the metabolic syndrome (MetS) and proteinuria in non-diabetic and type 2 diabetic men and women

\begin{tabular}{|c|c|c|c|c|c|c|c|c|c|c|}
\hline & \multicolumn{5}{|l|}{ Non-diabetic } & \multicolumn{5}{|c|}{ Type 2 diabetic } \\
\hline & \multicolumn{2}{|l|}{ Men } & \multicolumn{2}{|l|}{ Women } & \multirow{2}{*}{$\begin{array}{l}\text { Interaction } \times \\
\operatorname{sex}(p)\end{array}$} & \multicolumn{2}{|c|}{ Men } & \multicolumn{2}{|l|}{ Women } & \multirow{2}{*}{$\begin{array}{l}\text { Interaction } \times \\
\operatorname{sex}(p)\end{array}$} \\
\hline & $\operatorname{HR}(95 \% \mathrm{CI})$ & $p$ & HR $(95 \% \mathrm{CI})$ & $p$ & & $\mathrm{HR}(95 \% \mathrm{CI})$ & $p$ & $\operatorname{HR}(95 \% \mathrm{CI})$ & $p$ & \\
\hline \multicolumn{11}{|l|}{ Model 1} \\
\hline MetS & $1.6(0.9-2.7)$ & 0.090 & $4.0(1.7-9.7)$ & 0.002 & 0.072 & $1.5(1.1-2.0)$ & 0.024 & $1.1(0.8-1.5)$ & 0.622 & 0.206 \\
\hline $\mathrm{UP} \geq 0.1 \mathrm{~g} / 1$ & $1.5(0.9-2.4)$ & 0.123 & $1.8(0.8-4.2)$ & 0.175 & 0.407 & $1.6(1.0-2.6)$ & 0.036 & $1.6(1.1-2.3)$ & 0.008 & 0.403 \\
\hline $\mathrm{UP} \geq 0.2 \mathrm{~g} / 1$ & $1.4(0.8-2.5)$ & 0.295 & $4.0(1.5-10.5)$ & 0.006 & 0.019 & $1.6(1.1-2.2)$ & 0.013 & $1.9(1.3-2.6)$ & $<0.001$ & 0.822 \\
\hline \multicolumn{11}{|l|}{ Model 3} \\
\hline MetS & $1.5(0.9-2.6)$ & 0.153 & $3.8(1.6-9.2)$ & 0.003 & 0.061 & $1.4(1.0-1.9)$ & 0.077 & $1.0(0.7-1.4)$ & 0.893 & 0.227 \\
\hline UP continuous & $1.4(1.0-1.8)$ & 0.023 & $1.6(1.0-2.7)$ & 0.046 & 0.288 & $1.3(1.1-1.6)$ & 0.002 & $1.4(1.2-1.6)$ & $<0.001$ & 0.709 \\
\hline
\end{tabular}

In Model 1 urinary protein (UP) is presented as a dichotomous variable with a cut-off of $0.1 \mathrm{~g} / 1$, in Model 2 with a cut-off of $0.2 \mathrm{~g} / 1$ and in Model 3 as a continuous variable g/l (log). The models also include age, area of residence, current smoking and total cholesterol

Table 5 Cox model for cardiovascular disease death with all listed variables included, and adjusted for age, area of residence, smoking and total cholesterol

\begin{tabular}{|c|c|c|c|c|c|c|c|c|c|}
\hline & \multicolumn{3}{|c|}{ Urinary protein $\geq 0.1 \mathrm{~g} / 1$} & \multicolumn{3}{|c|}{ Urinary protein $\geq 0.2 \mathrm{~g} / 1$} & \multicolumn{3}{|c|}{ Urinary protein (continuous ${ }^{\mathrm{a}}$ ) } \\
\hline & HR & HR 95\% CI & $p$ & HR & HR 95\% CI & $p$ & HR & HR 95\% CI & $p$ \\
\hline \multicolumn{10}{|l|}{ Non-diabetic men } \\
\hline Obesity $^{c}$ & 0.9 & $0.4-2.0$ & 0.855 & 0.9 & $0.4-1.9$ & 0.736 & 0.8 & $0.4-1.9$ & 0.673 \\
\hline Hypertension $^{\mathrm{d}}$ & 1.5 & $0.9-2.5$ & 0.106 & 1.5 & $0.9-2.5$ & 0.108 & 1.5 & $0.9-2.5$ & 0.116 \\
\hline Proteinuria & 1.4 & $0.9-2.3$ & 0.159 & 1.3 & $0.7-2.4$ & 0.384 & 1.4 & $1.0-1.8$ & 0.029 \\
\hline \multicolumn{10}{|l|}{ Non-diabetic women } \\
\hline Hyperinsulinaemia $^{\mathrm{b}}$ & 2.9 & $1.1-8.1$ & 0.040 & 2.8 & $1.0-7.6$ & 0.045 & 2.9 & $1.1-8.1$ & 0.040 \\
\hline Obesity $^{\mathrm{c}}$ & 1.2 & $0.5-3.4$ & 0.668 & 1.2 & $0.4-3.2$ & 0.730 & 1.2 & $0.4-3.3$ & 0.736 \\
\hline Hypertension $^{\mathrm{d}}$ & 3.7 & $1.0-12.9$ & 0.043 & 3.4 & $1.0-12.1$ & 0.053 & 3.7 & $1.1-13.0$ & 0.039 \\
\hline Hyperinsulinaemia $^{\mathrm{b}}$ & 1.2 & $0.8-1.7$ & 0.446 & 1.1 & $0.8-1.7$ & 0.511 & 1.1 & $0.7-1.7$ & 0.626 \\
\hline Obesity $^{\mathrm{c}}$ & 1.3 & $0.9-1.9$ & 0.165 & 1.4 & $0.9-2.0$ & 0.114 & 1.3 & $0.9-1.9$ & 0.131 \\
\hline Hypertension $^{\mathrm{d}}$ & 1.3 & $0.8-2.0$ & 0.276 & 1.2 & $0.8-1.8$ & 0.472 & 1.2 & $0.8-1.8$ & 0.483 \\
\hline Dyslipidaemia $^{\mathrm{e}}$ & 1.2 & $0.8-1.8$ & 0.279 & 1.2 & $0.8-1.8$ & 0.338 & 1.2 & $0.8-1.8$ & 0.367 \\
\hline Elevated fasting glucose ${ }^{\mathrm{f}}$ & - & - & - & - & - & - & - & - & - \\
\hline Proteinuria & 1.6 & $1.0-2.5$ & 0.047 & 1.5 & $1.1-2.2$ & 0.023 & 1.3 & $1.1-1.6$ & 0.004 \\
\hline \multicolumn{10}{|l|}{ Diabetic women } \\
\hline Hyperinsulinaemia $^{\mathrm{b}}$ & 0.9 & $0.7-1.3$ & 0.713 & 0.9 & $0.6-1.3$ & 0.706 & 0.9 & $0.6-1.3$ & 0.526 \\
\hline Obesity $^{c}$ & 1.1 & $0.8-1.5$ & 0.741 & 1.1 & $0.8-1.5$ & 0.619 & 1.1 & $0.8-1.5$ & 0.767 \\
\hline Hypertension $^{\mathrm{d}}$ & 1.1 & $0.7-1.9$ & 0.598 & 1.1 & $0.7-1.8$ & 0.718 & 1.1 & $0.7-1.8$ & 0.670 \\
\hline
\end{tabular}

${ }^{a}$ Logarithmic transformation

${ }^{b}$ Fasting plasma insulin $\geq$ highest quartile of the non-diabetic subjects

${ }^{\mathrm{c}} \mathrm{BMI}>30 \mathrm{~kg} / \mathrm{m}^{2}$

${ }^{\mathrm{d} S y s t o l i c} \mathrm{BP} \geq 140 \mathrm{mmHg}$ or diastolic $\mathrm{BP} \geq 90 \mathrm{mmHg}$ or antihypertensive treatment

eTriglycerides $\geq 1.7 \mathrm{mmol} / 1$ or $\mathrm{HDL}<0.9 / 1.0 \mathrm{mmol} / 1$ in $\mathrm{men} /$ women

f $\geq 6.1 \mathrm{mmol} / 1$

$H R$ hazards ratio 
The Kaplan-Meier curves outline the cumulative incidence of CVD death in the composite groups during 18 years of follow-up (Fig. 2).

We also analysed the independent predictive value of metabolic syndrome and urinary protein by entering both of these variables simultaneously into multivariate adjusted Cox models (Table 4). Metabolic syndrome was an independent predictor of CVD mortality in non-diabetic women and in diabetic men. Urinary protein with a cut-off point of $0.1 \mathrm{~g} / \mathrm{l}$ was an independent predictor of CVD mortality in diabetic men and diabetic women, as was urinary protein with a cut-off point of $0.2 \mathrm{~g} / \mathrm{l}$ in non-diabetic women and diabetic subjects, and urinary protein as a continuous variable in all four groups.

A significant interaction between sex and metabolic syndrome was observed in the prediction of CVD death in non-diabetic subjects (Table 4). In the pooled data of nondiabetic and diabetic subjects an interaction between diabetes status and metabolic syndrome in the prediction of CVD mortality was observed in women ( $p$-values 0.002 0.003 depending on urinary protein cut-offs), with a higher hazard ratio (HR) of metabolic syndrome on the risk of CVD death in non-diabetic women than in diabetic women. In men, interaction between diabetes status and metabolic syndrome was not statistically significant.

Finally, we performed statistical analyses for each component of metabolic syndrome and urinary protein (cut-off points of $0.1,0.2 \mathrm{~g} / \mathrm{l}$, and as a continuous variable) to predict CVD mortality, adjusted for age, area of residence, smoking and total cholesterol (Table 5). Urinary protein was an independent predictor of CVD mortality with a cut-off of $0.1 \mathrm{~g} / 1$ in diabetic subjects, with a cut-off of $0.2 \mathrm{~g} / \mathrm{l}$ in non-diabetic women and diabetic subjects, and as a continuous variable in all four groups. Other independent CVD predictors were hyperinsulinaemia, hypertension and dyslipidaemia among non-diabetic women, and dyslipidaemia in diabetic women.

\section{Discussion}

Our study, based on the 18-year follow-up of non-diabetic and type 2 diabetic subjects from the same geographically defined population, demonstrated that proteinuria as a continuous variable predicted increased risk of CVD mortality in non-diabetic and diabetic subjects, independently of the presence of metabolic syndrome, without any consistent sex-related difference. Among non-diabetic subjects, metabolic syndrome was a stronger predictor of CVD risk in women than in men, whereas among diabetic subjects metabolic syndrome predicted CVD risk only in men.

Our finding that metabolic syndrome predicted CVD death is in agreement with results from previous studies in non-diabetic [27-29] and type 2 diabetic subjects [30, 31]. In the study of Bonora et al. [30], no sex-related differences were found in the prediction of CVD among type 2 diabetic patients. Our finding that among non-diabetic subjects metabolic syndrome was a stronger predictor of CVD mortality in women than in men is of interest. This finding is supported by the Atherosclerosis Risk in Communities Study, which showed that the association of metabolic syndrome by the National Cholesterol Education Program (NCEP) definition with the risk of incident coronary heart disease and stroke was stronger in women than in men, and that there was a statistically significant interaction with sex [32]. In the San Antonio Heart Study the association of metabolic syndrome (NCEP definition) with CVD mortality was about twice as strong in women than in men in the general population, although the sex difference was not statistically significant [33]. In the Second National Health and Nutrition Study Examination Survey the association of metabolic syndrome (NCEP definition) with CVD mortality was slightly stronger in women than in men, but an interaction with sex was not significant [34]. Our finding that several individual components of metabolic syndrome by the WHO definition (insulin resistance, raised blood pressure and dyslipidaemia) were independent predictors of CVD mortality in non-diabetic women but not in nondiabetic men (Table 5) suggests that the impact of risk factor clustering with insulin resistance may have a stronger effect on CVD risk in women than in men.

Our finding that proteinuria alone predicted CVD is also in accord with findings from other studies [1-12]. Microalbuminuria has been shown to be related to insulin resistance and hyperinsulinaemia [35-39], and other components of metabolic syndrome, including blood pressure $[40,41]$, high levels of triglycerides and apolipoprotein B $[42,43]$ and obesity [44]. When the 1998 WHO Consultation report [13] introduced microalbuminuria as a component of metabolic syndrome, this decision was evidently based on the association of microalbuminuria with insulin resistance and other components of metabolic syndrome. Our logistic regression analyses of cross-sectional associations between proteinuria and metabolic syndrome and its individual components showed, however, that these associations were not particularly strong, although urinary protein excretion increased linearly with an increasing number of metabolic syndrome components present. A significant finding of our study was that in non-diabetic men and women elevated fasting glucose within the nondiabetic range was associated with proteinuria, suggesting that even minor impairments in glucose regulation may enhance the development of glomerular leakage.

The causal relationship of microalbuminuria and proteinuria with the components of metabolic syndrome remains unclear. At least two possibilities have to be considered when trying to explain the association of proteinuria with CVD risk in prospective studies. Firstly, the clustering of several risk factors, including obesity, impaired glucose regulation, dyslipidaemia and hypertension, may be the primary abnormality leading to endothelial dysfunction. Proteinuria may be a manifestation of this damage and thus secondary to risk factor abnormalities. In this case, the development of risk factor abnormalities would be the underlying factor and proteinuria a sign of resulting preclinical vascular damage, which predicts the risk of clinical manifestations of atherosclerotic disease. Secondly, endothelial dysfunction with glomerular protein leakage may be 
the primary abnormality and lead to the appearance of risk factor abnormalities characteristic of metabolic syndrome and increased risk of CVD. It has even been proposed that glomerular protein leakage would be a marker of a genetic predisposition to vascular disease [45]. The findings of the present study are compatible with the view that proteinuria is an indicator of an early vascular damage heralding the development of CVD.

A methodological limitation of our study is that at the baseline examination, performed more than 20 years ago, we measured total urinary protein concentration from spot urine samples with the Coomassie brilliant blue method, instead of using a specific assay for albumin [46-48] which constitutes about one-half of total urinary protein [49]. Correlation of albuminuria with proteinuria has been previously documented with convergence toward the line of unity with increasing degrees of proteinuria [50]. We analysed our data using two different cut-offs to define proteinuria, namely urinary protein concentrations of $\geq 0.1$ and $\geq 0.2 \mathrm{~g} / \mathrm{l}$, and the results obtained with regard to the predictive impact of proteinuria were consistent with each other. Urinary protein as a continuous variable also yielded similar results. These low urinary protein cut-offs points were chosen to mimic microalbuminuria.

The strength of our study is that at baseline all essential components of metabolic syndrome were measured, including fasting insulin as a surrogate marker for insulin resistance. A complete follow-up in regard to cause-specific mortality is also an important advantage. However, caution is needed in extrapolating results from proteinuria, generally considered as a sign of a renal disease, to microalbuminuria or albuminuria, generally considered as a sign of endothelial dysfunction.

In conclusion, our study showed that proteinuria as a continuous variable predicted CVD mortality independently of the presence of metabolic syndrome in non-diabetic and type 2 diabetic subjects. Metabolic syndrome predicted CVD mortality in non-diabetic women and in diabetic men, independently of the presence of proteinuria.

\section{References}

1. Schmitz A, Vaeth M (1988) Microalbuminuria: a major risk factor in non-insulin-dependent diabetes. A 10-year follow-up study of 503 patients. Diabet Med 5:126-134

2. Mattock MB, Morrish NJ, Viberti G, Keen H, Fitzgerald AP, Jackson G (1992) Prospective study of microalbuminuria as predictor of mortality in NIDDM. Diabetes 41:736-741

3. Mogensen CE, Damsgaard EM, Froland A, Nielsen S, de Fine Olivarius N, Schmitz A (1992) Microalbuminuria in noninsulin-dependent diabetes. Clin Nephrol 38(Suppl 1):S28-S39

4. Beatty OL, Ritchie CM, Bell PM, Hadden DR, Kennedy L, Atkinson AB (1995) Microalbuminuria as identified by a spot morning urine specimen in non-insulin-treated diabetes: an eight-year follow-up study. Diabet Med 12:261-266

5. Miettinen $H$, Haffner SM, Lehto S, Rönnemaa T, Pyörälä K, Laakso M (1996) Proteinuria predicts stroke and other atherosclerotic vascular disease events in nondiabetic and noninsulin-dependent diabetic subjects. Stroke 27:2033-2039
6. Dinneen SF, Gerstein HC (1997) The association of microalbuminuria and mortality in non-insulin-dependent diabetes mellitus. A systematic overview of the literature. Arch Intern Med 157:1413-1418

7. Valmadrid CT, Klein R, Moss SE, Klein BE (2000) The risk of cardiovascular disease mortality associated with microalbuminuria and gross proteinuria in persons with older-onset diabetes mellitus. Arch Intern Med 160:1093-1100

8. Yudkin JS, Forrest RD, Jackson CA (1988) Microalbuminuria as predictor of vascular disease in non-diabetic subjects. Islington Diabetes Survey. Lancet 2:530-533

9. Damsgaard EM, Froland A, Jorgensen OD, Mogensen CE (1990) Microalbuminuria as predictor of increased mortality in elderly people. BMJ 300:297-300

10. Kuusisto J, Mykkänen L, Pyörälä K, Laakso M (1995) Hyperinsulinemic microalbuminuria. A new risk indicator for coronary heart disease. Circulation 91:831-837

11. Borch-Johnsen K, Feldt-Rasmussen B, Strandgaard S, Schroll M, Jensen JS (1999) Urinary albumin excretion. An independent predictor of ischemic heart disease. Arterioscler Thromb Vasc Biol 19:1992-1997

12. Hillege HL, Fidler V, Diercks GF (2002) Urinary albumin excretion predicts cardiovascular and noncardiovascular mortality in general population. Circulation 106:1777-1782

13. Alberti KG, Zimmet PZ (1998) Definition, diagnosis and classification of diabetes mellitus and its complications: Part 1. Diagnosis and classification of diabetes mellitus provisional report of a WHO consultation. Diabet Med 15:539-553

14. Balkau B, Charles MA (1999) Comment on the provisional report from the WHO consultation. European Group for the Study of Insulin Resistance (EGIR). Diabet Med 16:442-443

15. Jager A, Kostense PJ, Nijpels G, Heine RJ, Bouter LM, Stehouwer CD (1998) Microalbuminuria is strongly associated with NIDDM and hypertension, but not with the insulin resistance syndrome: the Hoorn Study. Diabetologia 41:694-700

16. Bigazzi R, Bianchi S, Campese VM, Baldari G (1992) Prevalence of microalbuminuria in a large population of patients with mild to moderate essential hypertension. Nephron 61:94-97

17. Foyle WJ, Carstensen E, Fernandez MC, Yudkin JS (1995) Longitudinal study of associations of microalbuminuria with the insulin resistance syndrome and sodium-lithium countertransport in nondiabetic subjects. Arterioscler Thromb Vasc Biol 15:1330-1337

18. Toft I, Bonaa KH, Eikrem J, Bendiksen AL, Iversen H, Jenssen $\mathrm{T}$ (2002) Microalbuminuria in hypertension is not a determinant of insulin resistance. Kidney Int 61:1445-1452

19. Cirillo M, Senigalliesi L, Laurenzi M et al. (1998) Microalbuminuria in nondiabetic adults: relation of blood pressure, body mass index, plasma cholesterol levels, and smoking: the Gubbio Population Study. Arch Intern Med 158:1933-1939

20. Abuaisha B, Kumar S, Malik R, Boulton AJ (1998) Relationship of elevated urinary albumin excretion to components of the metabolic syndrome in non-insulin-dependent diabetes mellitus. Diabetes Res Clin Pract 39:93-99

21. Cubeddu LX, Hoffmann IS, Aponte LM et al. (2003) Role of salt sensitivity, blood pressure, and hyperinsulinemia in determining high upper normal levels of urinary albumin excretion in a healthy adult population. Am J Hypertens 16:343-349

22. Laakso M, Rönnemaa T, Pyörälä K, Kallio V, Puukka P, Penttilä I (1988) Atherosclerotic vascular disease and its risk factors in non-insulin-dependent diabetic and nondiabetic subjects in Finland. Diabetes Care 11:449-463

23. World Health Organization (1983) Proposal for the Multinational Monitoring of Trends and Determinants in Cardiovascular Disease and Protocol (MONICA Project). World Health Organization, Geneva

24. Walker AE, Robins M, Weinfeld FD (1981) The National Survey of Stroke. Clinical findings. Stroke 12:I13-I44

25. Van Kley H, Hale SM (1977) Assay for protein by dye binding. Anal Biochem 81:485-487 
26. Hu G, Qiao Q, Tuomilehto J, Balkau B, Borch-Johnsen K, Pyörälä K (2004) Prevalence of the metabolic syndrome and its relation to all-cause and cardiovascular mortality in nondiabetic European men and women. Arch Intern Med 164:1066-1076

27. Isomaa B, Almgren P, Tuomi T et al. (2001) Cardiovascular morbidity and mortality associated with the metabolic syndrome. Diabetes Care 24:683-689

28. Lakka HM, Laaksonen DE, Lakka TA et al. (2002) The metabolic syndrome and total and cardiovascular disease mortality in middle-aged men. JAMA 288:2709-2716

29. Bonora E, Kiechl S, Willeit J et al. (2003) Metabolic syndrome: epidemiology and more extensive phenotypic description. Cross-sectional data from the Bruneck Study. Int J Obes Relat Metab Disord 27:1283-1289

30. Bonora E, Targher G, Formentini G et al. (2004) The metabolic syndrome is an independent predictor of cardiovascular disease in type 2 diabetic subjects. Prospective data from the Verona Diabetes Complications Study. Diabet Med 21:52-58

31. Bruno G, Merletti F, Biggeri A et al. (2004) Metabolic syndrome as a predictor of all-cause and cardiovascular mortality in type 2 diabetes: the Casale Monferrato Study. Diabetes Care 27:2689-2694

32. McNeill AM, Rosamond WD, Girman CJ et al. (2005) The metabolic syndrome and 11-year risk of incident cardiovascular disease in the Atherosclerosis Risk in Communities Study. Diabetes Care 28:385-390

33. Hunt KJ, Resendez RG, Williams K, Haffner SM, Stern MP (2004) National Cholesterol Education Program versus World Health Organization metabolic syndrome in relation to all-cause and cardiovascular mortality in the San Antonio Heart Study. Circulation 110:1251-1257

34. Malik S, Wong ND, Franklin SS et al. (2004) Impact of the metabolic syndrome on mortality from coronary heart disease, cardiovascular disease, and all causes in United States adults. Circulation 110:1245-1250

35. Mykkänen L, Haffner SM, Kuusisto J, Pyörälä K, Laakso M (1994) Microalbuminuria precedes the development of NIDDM. Diabetes 43:552-557

36. Agewall S, Fagerberg B, Attvall S (1995) Microalbuminuria, insulin sensitivity and haemostatic factors in non-diabetic treated hypertensive men. Risk Factor Intervention Study Group. J Intern Med 237:195-203

37. Bianchi S, Bigazzi R, Quinones Galvan A et al. (1995) Insulin resistance in microalbuminuric hypertension. Sites and mechanisms. Hypertension 26:789-795
38. Mykkänen L, Zaccaro DJ, Wagenknecht LE, Robbins DC Gabriel M, Haffner SM (1998) Microalbuminuria is associated with insulin resistance in nondiabetic subjects: the Insulin Resistance Atherosclerosis Study. Diabetes 47:793-800

39. El-Atat FA, Stas SN, McFarlane SI, Sowers JR (2004) The relationships between hyperinsulinemia, hypertension and progressive renal disease. J Am Soc Nephrol 15:2816-2827

40. Cerasola G, Cottone S, Mule G et al. (1996) Microalbuminuria, renal dysfunction and cardiovascular complication in essential hypertension. J Hypertens 14:915-920

41. Redon J, Liao Y, Lozano JV, Miralles A, Baldo E, Cooper RS (1994) Factors related to the presence of microalbuminuria in essential hypertension. Am J Hypertens 7:801-807

42. Winocour PH, Harland JO, Millar JP, Laker MF, Alberti KG (1992) Microalbuminuria and associated cardiovascular risk factors in the community. Atherosclerosis 93:71-81

43. Haffner SM, Stern MP, Gruber MK, Hazuda HP, Mitchell BD, Patterson JK (1990) Microalbuminuria. Potential marker for increased cardiovascular risk factors in nondiabetic subjects? Arteriosclerosis 10:727-731

44. Tapp RJ, Shaw JE, Zimmet PZ et al. (2004) Albuminuria is evident in the early stages of diabetes onset: results from the Australian Diabetes, Obesity, and Lifestyle Study (AusDiab). Am J Kidney Dis 44:792-798

45. Yudkin JS (1992) Microalbuminuria: a genetic link between diabetes and cardiovascular disease? Ann Med 24:517-522

46. Ginsberg JM, Chang BS, Matarese RA, Garella S (1983) Use of single voided urine samples to estimate quantitative proteinuria. N Engl J Med 309:1543-1546

47. Ralston SH, Caine N, Richards I, O'Reilly D, Sturrock RD, Capell HA (1988) Screening for proteinuria in a rheumatology clinic: comparison of dipstick testing, 24 hour urine quantitative protein, and protein/creatinine ratio in random urine samples. Ann Rheum Dis 47:759-763

48. Agrawal B, Berger A, Wolf K, Luft FC (1996) Microalbuminuria screening by reagent strip predicts cardiovascular risk in hypertension. J Hypertens 14:223-228

49. Mogensen CE, Schmitz O (1988) The diabetic kidney: from hyperfiltration and microalbuminuria to end-stage renal failure. Med Clin North Am 72:1465-1492

50. Atkins RC, Briganti EM, Zimmet PZ, Chadban SJ (2003) Association between albuminuria and proteinuria in the general population: the AusDiab Study. Nephrol Dial Transplant $18: 2170-2174$ 